\title{
EL MOMENTO DE LO VIVO: INFORME DEL COLOQUIO DE CERISY
}

Christine BARON

Universidad de Poitiers

christine.baron@univ-poitiers.fr

El coloquio El momento de lo vivo, codirigido por Fréderic Worms y Arnaud François, que tuvo lugar en Cerisy del 16 al 23 de agosto de 2012, reunió a filósofos y a científicos; biólogos, médicos, físicos, especialistas en literatura, un historiador, un especialista en ecología y un artista dedicado al trabajo «en vivo» y al que se podría vincular con el bio-arte se concertaron para reflexionar no sobre el concepto de la vida sino sobre lo que - bajo diversos aspectos - tiene de específico lo vivo.

En primer lugar, ¿por qué este título? Lo vivo es, primeramente un «momento» de nuestra vida; el de la llegada al mundo, el de acontecimientos que conciernen a nuestras relaciones con los otros vivos, pero también paradójicamente el momento en que la muerte y la enfermedad amenazan esos equilibrios de lo vivo, equilibrios invisibles mientras nada venga a descompensarlos, como señala Canguilhem en su opúsculo sobre la salud. El momento de lo vivo es igualmente ese momento de nuestra historia, en el paso del siglo XX al XXI, en el que, en todos los campos, las evoluciones de la biología celular nos obligan a repensar nuestra relación con la vida, y en el que lo vivo es objeto de una atención particular reflejada por términos que han entrado masivamente en nuestro vocabulario: bio-política, bio-economía, bio-ética, bio-poética. El cruce de estos diversos campos nos impone repensar la relación que mantenemos con lo vivo como objeto científico, como concepto, como categoría política, como experiencia cotidiana de nuestro propio cuerpo vivido en el dolor o en el placer.

\section{Recorridos filosóficos}

En primer lugar, Frédéric Worms subraya la doble tentación a la que conviene sustraerse; la del reduccionismo científico, que no vería en lo vivo sino la actualización (y la reproducción) de una vida celular, y que determinaría lo vivo como categoría exclusivamente material para uso científico. Lo vivo se caracteriza también por una ampliación de la vida biológica a la vida como proyecto, en particular cuando se trata de la vida humana. Por otra parte, lo vivo —en tanto que categoría a la que 
pertenecemos y que comprende a todos los otros seres (animales, vegetales) — incita a la acción; nos incumbe describirlo y también preservarlo, protegerlo en sus diversas formas, pues es lo que nos rodea, y también nosotros somos seres vivos. Esta implicación del hombre en lo vivo ha sido subrayada en múltiples ocasiones durante el coloquio (mediante la fórmula evocadora, y también de sentido trivial, de «estar dentro»). Ya se trate de la relación del hombre y del animal, o de la relación con su medio natural, o de la enfermedad y la salud, la idea recurrente del rechazo de un estatuto de excepción de lo humano ha constituido un hilo conductor de la reflexión, unas veces contestada (como en el caso de la contribución de Etienne Bimbenet, «El hombre y el animal; ¿qué comunidad?») y otras reivindicada (en la contribución de Anne Simon, «Hombres y animales en vivo; trastornos en la domesticación y literatura contemporánea»). ¿Cómo ha pensado la filosofía la inclusión o la exterioridad del hombre frente a la naturaleza, esa naturaleza que ha sido primeramente en la filosofía el «otro viviente» (un viviente «otro») respecto del cual nos definimos? La ecología global y las reflexiones de Roberto Espósito (2012) sobre esta globalidad de lo vivo suponen una toma de conciencia política que desemboca en cambios de paradigma radicales relativos a la vida. Defender la vida supone otro modelo de desarrollo humano; de relación con el animal, de situación del hombre con respecto a la naturaleza.

Lo vivo puede ser descrito filosóficamente a través de la noción de movimiento; desde Maine de Biran a Bergson (en La pensée et le mouvant), o desde Michel Henry y Merleau-Ponty, releído par Renaud Barbaras (2011), Anne Devarieux traza una genealogía de estas filosofías que establecen el movimiento como condición de la vida. Elegir este paradigma supone sobrepasar un dualismo sujeto / objeto tradicional en las filosofías del conocimiento y que no logra designar claramente la vida; el modo de ser propio de lo vivo designa comúnmente en esos textos la esencia de todo movimiento. Ese movimiento es irreductible a la movilidad: es el movimiento carnal del «yo puedo» pues, para Michel Henry, la biología no nos dice nada de lo vivo. La teoría del cuerpo subjetivo implica una inmanencia radical; la de la distancia concreta, individual, absoluta, de un «soy mi cuerpo» idéntico a la estructura del ego. Pero a la adscripción pura del «sentirse uno mismo» de Michel Henry, Barbaras confronta el movimiento ya no virtual sino actual del deseo. Al oponerse a la intransitividad de Henry, y al oponer la transitividad del deseo a esa autarquía del sujeto, está proponiendo una negatividad en el seno del sujeto viviente, una laguna que nos es necesario pensar. ¿Pensar lo vivo nos confronta acaso necesariamente con esa alternativa entre una trascendencia del mundo y un exceso enteramente colocado en el lado del sujeto? Sin duda es necesario encontrar otros marcos para escapar a esta alternativa imposible.

Mediante un amplio barrido histórico de las filosofías que han problematizado la cuestión de la naturaleza, Paul-Antoine Miquel y Pierre Montebello trazan una cartografía de esos pensamientos de la naturaleza, de la transición del modelo físico al modelo vivo como paradigma científico. La importancia de este recorrido está ligada al hecho de que, desde la distinción cartesiana entre res extensa y res cogitans, el hombre siente que pertenece a la naturaleza. Una vez abandonado el modelo del cosmos griego, parece que el hombre occidental se concibiera a sí mismo como si hubiera llegado completamente hecho a la tierra, cuando lo cierto es que se ha constituido en la historia de lo viviente. 
Desde el gnosticismo hasta Jonas, pasando por Heiddeger y el Dasein, la hospitalidad ha sido sustituida por la hostilidad de un mundo irracional e incluso diabólico (Montebello).

Los avances científicos en el campo de lo vivo no han hecho ceder el malestar del que da cuenta Derrida en L'Animal que donc je suis, en el que se elabora una respuesta a este antropocentrismo amnésico que sustrae al hombre del mundo de las criaturas vivientes. Pensar la solidaridad de los seres naturales se convierte en la tarea de una filosofía que intenta reparar ese olvido viendo entre los seres vivos diferencias de grado, no de naturaleza. La filosofía de Simondon (1995), que piensa esta continuidad como participación y relación ha establecido un hilo invisible entre estas reflexiones; de hecho se le dedicará un coloquio en Cerisy en 2013. Se evoca también a otros pensadores de la continuidad - Muriel Combes, Jean-Marie Schaeffer y, en el campo de la antropología, Philippe Descola (2006) — , y la cuestión se desplaza del lado de la acción, pues la naturaleza no se manifiesta más que en la medida en que participamos de ella. ¿Qué es lo que el hombre puede en su encuentro con estas vidas?

Lo vivo se reconduce pues hacia la praxis en la contribución de Rocco Ronchi, quien plantea cuestiones a los textos de Bergson y de Gentile, textos en los que la praxis se ve opuesta a la poiesis en la medida en que mantiene abierto un convertirse en acto, en tensión hacia un objetivo, una praxis teleia. Pensar lo vivo a partir del movimiento da un nuevo punto de partida que es el de la individuación (Simondon) o de lo que Rocco Ronchi llama la "disyunción en acto", pues no se trata de desunir en nombre de una unidad de concepto, sino de concebir lo vivo como progresión, con una duración creadora.

\section{Recorridos científicos}

La cuestión de la duración es planteada por el físico Marc Lachieze-Rey, quien recuerda hasta qué punto desde el descubrimiento de la teoría de la relatividad ningún tiempo es coexistente con otro. Los vivos poseen así sus duraciones propias, irreductibles unas a otras, lo que nos obliga a disociar sucesión y causalidad. Esto no deja de tener efectos en nuestra percepción de lo vivo. Jean-Claude Ameisen transmite esta complejización cuando, con ayuda de numerosos ejemplos, anota que el genoma no es nada determinista. Volviendo al tema del tiempo: los relojes biológicos circadianos que funcionan en ciclos de veinticuatro horas y existen en ciertas plantas y bacterias tienen como característica, según Türing, una cadena de causalidades contradictorias que vuelve a llevar al sistema a su punto de partida. En nuestro cuerpo, cada célula se mide con un tiempo propio; todo un sistema de mensajes sincroniza esos relojes (el cerebro alimenta y regula esos ritmos). Las moscas drosophilas se sincronizan en veinticuatro horas incluso sin sol tras varias generaciones. ¿Acaso la sincronización entre los seres vivos es una propiedad emergente mayor?

La noción de interconexión de los seres vivos parece pertinente para pensar esos fenómenos. El debate entre Lamarck y Darwin vuelve a estar en el candelero, pero en modo más complejo; incluso aunque los caracteres adquiridos no se transmitan, el medio ambiente es un filtro (Wallace). ¿Está ya 
todo escrito en el huevo fecundado o lo que se encuentra presente es un campo de posibles en el que el medio ambiente va a trazar su surco? La cuestión central es la de la utilización de los genes por parte del cuerpo. Los genes pueden ser activados en un organismo, pero en un tubo de ensayo no producen nada. Los «intérpretes», la interacción con el medio, se convierten en esenciales. Las modalidades de utilización de los genes van a ser fuente de complejidad. El hecho de leer o no leer ciertos genes construye a los seres vivos en su singularidad. La epigénesis es ese fenómeno. Ameisen recuerda además que mutaciones genéticas del caernorhabditis elegans -ese pequeño gusano que tras la mutación ha permitido que se comprenda mejor el fenómeno de la apoptosis (Ameisen, 2002) — han dado lugar a ejemplares que permanecen jóvenes durante más tiempo. Una modificación de una secuencia es suficiente para producir este resultado. Paralelamente, si se reduce un factor del medio ambiente, la riqueza calórica de la alimentación por ejemplo, se obtiene el mismo resultado. Cuando el medio es más rico, las enfermedades no se desarrollan en las ratas en las que se ha introducido una modificación destinada a producir una patología; las relaciones con el medio juegan pues un papel importante en la formación de los seres vivos. Esas relaciones son independientes del tiempo, pero están sin embargo condicionadas por series discretas que acusan saltos o continuidades en el ser vivo que posee una temporalidad propia.

Esta reflexión sobre la temporalidad vuelve a ser objeto de reflexión en el marco de la medicina con la intervención de Daniel Sicard, quien insiste sobre un doble fenómeno de las sociedades modernas, y constata una paradoja: la enfermedad de Alzheimer es el horizonte de los finales de vida cada vez más larga: suscita rechazo y repulsión. Resulta que estos enfermos, que viven en un continuo presente, son el reflejo exacto de una sociedad afectada de amnesia colectiva. La desaparición de la historia de la medicina en la formación de los futuros médicos, la sustitución de la memoria viva por esas prótesis que son la memoria electrónica y el archivo en la red han modificado nuestra relación con el tiempo. Tenemos, de este modo, la ilusión de una memoria infinita y disponible en el ordenador y este «sucedáneo» nos lleva a ahorrar vanos esfuerzos. Pero la memoria es interacción con el mundo y el trenzado del conocimiento y de la emoción es esencial en la creatividad humana. El hecho de considerar la memoria como un stock de información según un modelo computacional nos impide comprender su conexión con la dimensión viva del individuo.

Por ello, la memoria de la Shoah se encuentra más marcada, en las representaciones colectivas, por las obras literarias que por los recuerdos o las noticias de los archivos. Lo que a menudo reflejan estos relatos es que el filtro del cuerpo retiene las escorias de un presente no jerarquizado, lo cual es el principio mismo de una memoria viviente, y por ello eventualmente olvidadiza, en todo caso selectiva. El hecho de no considerar este punto es muy inconveniente para el conocimiento y para la relación social. Lo que importa no es tanto un «deber de memoria» — esterilizante forma hipócrita del olvidosino un trabajo de memoria. Así, las conmemoraciones pueden enmascarar el resurgimiento de un antisemitismo enmascarado a su vez por esas mismas ceremonias.

La intervención de Eduardo Dei Cas se centra en la noción de emergencia. La emergencia es una noción coherente con la singularidad de lo vivo en la medida de que las propiedades emergentes de un 
individuo no son deducibles de las partes constituidas. Lo vivo es emergente, es decir, asimétrico, no lineal, no predecible.

Pensar una ética de lo vivo supone una atención particular no solamente a esta movilidad sino a la continuidad de lo vivo. Así pues, el hombre no es necesariamente «víctima» de patologías o de virus procedentes del animal (como pudiera hacer pensar la expresión «gripe aviar», por ejemplo); él mismo es vector viral, y en tanto que tal se ve incluido en la cadena de lo vivo.

\section{Animalidad, humanidad, lenguaje}

De hecho, esta cadena de lo vivo no es una evidencia desde el momento en que el hombre concibe al mismo tiempo su inclusión en lo vivo y su exterioridad respecto de las especies animales. La contribución de d'Etienne Bimbenet se fija en esta exterioridad. Comentando las tesis de Derrida (L'Animal que donc je suis) y de Jean-Marie Schaeffer en La fin de l'exception humaine, subraya que están determinadas por tres factores:

- El evolucionismo y la emergencia del instrumento genético, el desarrollo de la paleoantropología y del cognitivismo (que supone mecanismos comunes al hombre y al animal).

- Una sensibilidad moral activa que va en el sentido de una común consideración moral respecto de los animales. Así, para Peter Singer en The Expanding Circle nuestra guerra sacrificial y maltratadora para con el animal parece terminada.

- Una historia filosófica como fin de la metafísica que descarta ya como ilegítima la separación entre cuerpo y espíritu.

Todo ello viene impregnado de una nueva sensibilidad hacia el animal. Sin embargo, volver a una separación no es convertirse de nuevo en metafísico; se puede ser naturalista «de la segunda naturaleza» y percibir correspondencias mayores. El punto de vista subjetivo de la fenomenología ha de ser defendido, pues puede ofrecer otro relato de la antropogénesis. En efecto, mientras que el animal no percibe en su medio más que aquello que concierne a su acción inmediata y está centrado en sí mismo y sus propias necesidades, el hombre, dotado de una intencionalidad práctica, se relaciona con el mundo sin encontrarse encerrado en su «medio de vida».

La intencionalidad funcional se convierte en conciencia por el hecho de que «el mundo está ahí sin mí». Sin embargo, el animal no se representa un mundo autónomo. El hombre, al inventar la representación, tiene conciencia de su mortalidad. El mundo es lo que le va a sobrevivir, y lo que hace que participe a la génesis de un mundo común, de naturaleza ética y política.

En la orilla opuesta, Anne Simon se apoya sobre tres relatos para reivindicar esa disciplina emergente que es la ecopoética cuyo objeto es saber cómo las obras ponen en palabras nuestra manera de habitar nuestra morada. La pregunta supone una renovación de nuestra relación con los animales. Se encuentra ésta, en efecto, marcada por la violencia. En ciertos textos de Yves Bichet y Olivia Rosenthal (Que font les rennes après Noël?), la domesticación humana del niño se ve puesta en 
relación con la del animal y genera malestar. Los relatos que tratan de mataderos muestran que no es suficiente tener vida para estar vivo. Esos relatos siembran además confusión sobre la manera de nombrar al otro animal, ése que se encuentra sometido a un delirio regulador que pone en cuestión el lugar de la animalidad hoy en día. Esta extrema regulación de lo vivo aboca a la desregulación del sentido de la vida y a una deshumanización de lo humano. Al romper el contrato doméstico, el cazador caza sin peligro, pero los hombres que atentan contra lo vivo lo hacen a escondidas, excluyéndose así del mundo común.

Por otro lado, desde el punto de vista de las representaciones que tenemos del mundo animal, se pide a los animales que respondan a exigencias inconciliables. Como objetos de espectáculo en el zoo o en el circo, tienen por «misión» permanecer salvajes; vivir en un espacio cerrado, pero seguir siendo readaptables al medio salvaje. La alimentación de los animales del zoo se vuelve en extremo artificial, y las condiciones en que son albergados están reguladas jurídicamente, lo que hace de la naturaleza un verdadero equívoco. Los animales sirven de este modo para «domesticar» de nuevo una naturaleza a la que se está matando bajo apariencia de respeto. Pues, en un mundo natural encuadrado por los reglamentos humanos, los animales deben seguir siendo aquello que los hombres imaginan que son: objetos de consumo culinario, animales de circo.

A pesar de esta proximidad de los seres de la cadena de lo viviente, la palabra es algo esencial en la definición de lo vivo. Refiriéndose a Comprendre la musique de Boris Schoelzer — de 2011- y a la filosofía de Wittgenstein, Antonia Soulez observa en primer lugar que uno vive lo que expresa, y no a la inversa. Más que ser recibidos o dados, los objetos son conquistados por una actividad creadora del espíritu en la que el lenguaje otorga sentido. Sin lenguaje, el espíritu no puede dar forma al pensamiento. No existe un «órgano formador». Efectivamente, lo amorfo es la bestia negra de los filósofos (Aubenque). Husserl insiste sobre el material morfológico de la lengua. Pero formalizando la forma y haciendo empírico el material, no se da alcance a la vida, pues la vida de las formas se revela a través del hacer humano. Para Cassirer, esta actividad está en relación con una energeia (Herder) o trabajo del espíritu que no se resume en sus propios productos.

La mediación de la lengua desplaza la forma y su sentido e instaura relaciones energéticas entre material y forma. El trabajo de la ciencia puede entonces ser concebido según el modelo del arte. Consiste en «doblegarse» a lo real. En esa cooperación entre principio formal y principio material, la relación con el lenguaje existe antes que la vida. La lengua no es pues un «medio»y para el « $2^{\circ}$ Wittgenstein», «un enunciado que tiene sentido ha de nombrar objetos», estar del lado de la proposición y no de la designación. Esta condición destinada (dedicada) nos enseña que la lengua debe «desapegarse»: mediante el lenguaje, el objeto ya no es dado o recibido. El lenguaje articula visiones del mundo. Los elementos materiales y formales de la lengua están ligados, de ahí la importancia de la musicalidad de la lengua. ¿Por qué la música articula lenguaje y vida? Tenemos aquí la autonomía de una forma terminada al final del ciclo cuyo modelo puede ser encontrado en Hanslick ( Du Beau dans la musique). En contra de Wagner, de la emoción y de la idea romántica de que la música podría 
«expresar» algo exterior a ella, hay aquí una forma de adecuación de una vida a su proyecto, una articulación viva.

Así, la teoría del arte no es preexistente, es la expresión viva la que le da su forma.

\section{Biopolíticas, virología y gestión de la catástrofe}

El concepto de vida y la referencia a lo vivo han sido a veces utilizados para convertir en lícito lo inaceptable. Johann Chapoutotnos recuerda que el discurso nazi destinado a legitimar el eugenismo y las experiencias de laboratorio sobre los prisioneros de «raza inferior» fue primero un discurso sobre la vida alemana. Esta vida herida por los dos millones de muertos de la Primera Guerra Mundial debía ser reparada. El higienismo y las políticas de natalidad que se suponía iban a fortalecer la raza condujeron a las políticas de exterminio conocidas. La muerte organizada fue preparada técnicamente por médicos, e ideológicamente por un discurso sobre la vida y la «contaminación» que supuestamente transmitían los otros pueblos. Eso que se llamó una biopolítica era en realidad una tanatopolítica meticulosamente organizada. Pero la exaltación de la vida alemana se apoyó en una naturalización de esta política y una ideología de lo instintivo y de lo primario —abusivamente asimiladas a lo «vivo»— que bloqueaban de este modo toda forma de reflexividad. El odio del régimen nazi hacia los intelectuales es prueba de esta concepción truncada de la vida que se encuentra en el fundamento de la doctrina nazi.

La cuestión biopolítica emerge así a la sombra de las políticas de exterminio de los judíos durante las Segunda Guerra Mundial. Ese paradigma de pensamiento que ha sido el de Agamben en Homo sacer merecería volver a ser pensado hoy en día. Anne Gléonec lamenta la analogía del cuerpo político con el cuerpo como una suerte de pensamiento terminal. Describe «el instinto de muerte» del totalitarismo; cuerpo «uno» de la sociedad convertido en «cuerpo máquina». Éste es pensado en oposición con el «sin cuerpo» de la democracia, figura lábil de una sociedad en la que no afloraría otra cosa que la carne de lo social. La diferencia del nazismo con el comunismo (en materia de biopolítica) viene de su importancia y de su significación. La metáfora se ha convertido en realidad. Efectivamente, los políticos han elegido un principio médico-biológico para guiar sus acciones con voluntad de identificación entre política y biología. Esta perversión no es un accidente sino el télos de la biología realizada. Además, la categorización de la biopolítica se encuentra ligada a la cuestión de la inmunización. La enfermedad auto-inmune se desarrolla cuando el aparato protector se vuelve en contra del cuerpo mismo que debía proteger. La enfermedad que roe al nazismo es aquello contra lo que éste quería proteger al pueblo. Los judíos ya no se parecen a los parásitos; lo son, y el carácter literal de la metáfora tomada al pie de la letra nos impele a leerla en toda su radicalidad.

El cuerpo se convierte en sujeto de discriminación y exclusión; la política que habla del cuerpo no puede desprenderse si no es desde un pensamiento que pone distancia consigo mismo, y que considera a la metáfora como metáfora. Dos «salidas» (que pudieran resultar callejones) se 
presentarían entonces; rehusar pensar la vida en política para escapar a la biopolítica o intentar pensar una biopolítica positiva.

Esta segunda vía ha sido objeto de varias propuestas. Recordemos además que la primera vez que se utiliza la palabra —en boca de Starobinski- ésta implica una política mundial de salud y tiene un marcado sentido positivo. A partir de una investigación sobre la gripe aviar, cuando Hong Kong es considerado como punto neurálgico de observación virológica y lugar de paso entre Oriente y Occidente, Frédéric Keck inicia una reflexión sobre la noción de «biocentinela». Las estrategias que pretenden observar las evoluciones de lo vivo y la noción de «enfermedad centinela» son indicadores sanitarios que permiten anticipar catástrofes epidémicas. Lejos de excluir al animal de la comunidad, la noción de centinela lo integra en una cadena de lo viviente (también existen centinelas animales, en particular entre los pájaros). La teoría de lo vivo entra así en dialogo con la inmunología. La defensa inmunitaria es una manera de comunicar entre células. Puesto que el organismo puede ser destruido por esta sobre-reacción a lo patógeno, la centinela evalúa el riesgo e impide una catástrofe que alcanzaría al conjunto de lo viviente: tiene un papel informativo que concierne al mismo tiempo al «exterior» de la comunidad y a la comunidad misma.

$\mathrm{Al}$ analizar la dinámica de las catástrofes, Paul Dumouchel subraya el hecho de que éstas pueden encontrarse circunscritas en el tiempo o, al contrario, perpetuarse, y que lo que condiciona su duración es el valor de las anticipaciones que se pueden realizar sobre el comportamiento del otro; el «civismo» observado en Japón durante la catástrofe de Fukushima permitió reducir las consecuencias de la misma, aunque no su amplitud. Así pues, con respecto a los efectos sobre lo vivo, conviene distinguir las catástrofes naturales (en las que se plantean cuestiones cruciales de responsabilidad y de anticipación) de las catástrofes humanas, más susceptibles de perpetuarse en el tiempo.

Las catástrofes naturales, sobre todo de naturaleza ecológica, pueden ser evitadas mediante un cambio de paradigma en nuestra manera de enfocar la relación del hombre con la naturaleza (André Micoud). Considerar la naturaleza como una biosfera y patrimonializar los recursos vivos naturales (ecomuseos, parques) puede conducirnos a esa conversión motivada por el hecho de que lo vivo no es un depósito ilimitado al que se pueda acudir durante tiempo indefinido.

La noción de «desarrollo sostenible» recientemente forjada comporta tres dimensiones (Koselleck): económica, medioambiental y social. Es una categoría retórica y también normativa (objeto de convenios y tratados) que instituye una nueva relación con el tiempo de lo vivo.

\section{¿Hacia una biopolítica afirmativa?}

Ese tiempo de lo vivo implica también que las instituciones sanitarias y la manera en que los enfermos se apropian de su propia condición pueden constituir elementos que permitirían pensar de nuevo la biopolítica en términos que no fueran provenientes de Foucault. De este modo, para Florence Caeymaex et Julien Pieron, el cuerpo enfermo puede convertirse en un elemento de acceso a la ciudadanía. Caer enfermo es, de hecho, un motivo aceptable para la solicitud de legalización de los 
emigrantes. ¿Se puede entonces hablar de la valorización de la vida sin más, como cuando se saca a la escena mediática a enfermos jóvenes —en el caso del Téléthon- con el fin de que reciban donaciones? La intervención de Alain Kaufmann se hace preguntas sobre este asunto. Nicolas Rose, sociólogo y psicólogo, realiza una cartografía del presente de las biopolíticas. Didier Fassin publica en 2010 La Raison humanitaire, que propone variantes a la interpretación foucaultiana de las biopolíticas. Si toda biopolítica supone diferenciaciones complejas y arbitrajes, no es posible, sin embargo, establecer la sospecha como a priori de la discusión. Las propuestas de Latour (2000) en favor de una reconsideración del biopoder permiten no decidir de antemano sobre su poder liberador u opresivo.

A partir de esta «biolegitimidad», Alain Kaufmann propone una reflexión sobre la «biociudadanía». Procedente de la participación del enfermo y de su entorno en los cuidados, nace en la estela de las «enfermedades huérfanas»y de las asociaciones surgidas de los movimientos de protesta de las familias contra la «lentitud» de las investigaciones científicas. Fatalismo y pasividad han dejado paso a una actitud militante que pone a los pacientes al lado de los investigadores. Según la expresión de Rose y de Novas, se trata de proyectos de construcción de la ciudadanía, y la genómica es el nuevo vector de esta ciudadanía y la fuente de una biosocialidad, es decir, de una reapropiación del «biopoder» por parte de los enfermos y las familias. La vida y lo vivo se ven articulados por las asociaciones. La participación de las familias en la gobernanza de las redes de investigación es efectiva en la medida en que son ellas las que construyen y financian hospitales y redefinen criterios éticos (el «consentimiento informado»); Sharon Terry, activista de ese movimiento en USA invoca las nociones de «biocapital»y de «biovalor». Dejando de ser simples pacientes, los enfermos se convierten en socios de los investigadores. El marco comercial ha permitido la emergencia de ese modelo, y ha generado, por ejemplo, una bajada del coste de la secuenciación de alto flujo (para el ADN). Esta valorización de la enfermedad en cuanto tal es sin embargo ambigua: ciertas asociaciones reivindican una creciente responsabilidad, mientras que otras tratan de des-patologizar la enfermedad (es el caso de la de Asperger, y algunas formas de hiperactividad). En la biosocialidad, la naturaleza estudiada y la modificada gracias a las técnica se confrontan, y la pericia del entorno puede ser recabada como ayuda por el personal sanitario. Este modelo idílico tiene sin embargo límites: la concurrencia entre asociaciones, la apropiación comercial por parte de los laboratorios farmacéuticos y los efectos de lobbying no se encuentran ausentes de esta nueva socialidad.

La plataforma interdisciplinaria de ética Ethos, de Lausana, propone una interfaz paciente / sociedad descrita en esos términos, y Lazare Benaroyo concluye que es necesaria una hermenéutica de lo vivo en la práctica clínica consistente en cuatro tiempos: el despertar ético al sufrimiento, el momento deontológico de mediación social (momento teleológico del pacto de cuidados), el momento técnico (objetivación) y el momento de la sabiduría práctica (restauración de la autonomía del paciente; el paciente pilota su propia vida con la ayuda del médico).

En la misma línea de estas observaciones, y partiendo del Principe responsabilité de Jonas, Roland Schaer define lo vivo como aquello de lo que debemos responder. La mortalidad es pues la puerta estrecha por la que ha penetrado la cuestión del valor en la indiferencia constitutiva de lo vivo. 
El cuidado parental, compartido con los animales (y que no es exclusivo de la madre, ni siquiera de un pariente biológico, tal y como señala Frédérique Bisiaux), y también el cuidado médico, la cultura, así como las políticas de salud y la preocupación ecológica constituyen sendas ampliaciones de este principio. Pero sobre todo, lo que constituye el momento ético propio del cuidado es compartir la fragilidad de la vida. La responsabilidad consiste en pensar la inclusión de cada uno dentro de lo vivo, y no es ser solamente fiel a lo que enseña la investigación científica, sino que está en relación con el hecho de que nuestra condición viviente fija nuestra pertenencia al mundo.

Quien tiene un poder debe pues concebirse como parte integrante del mundo sobre el que actúa (condición esencial para la acción); su vulnerabilidad es un efecto del sistema, y la «habitabilidad» de un mundo común tiene en ello su origen.

Frente a esta vulnerabilidad, lo vivo debe ser objeto de cuidados específicos, en particular en el caso de los mamíferos. Frédérique Bisiaux analiza entonces el cuidado materno como un fenómeno del cuidado complejo en el que normas vitales, morales y sociales entran en juego. Se puede así constatar una paradoja; si hay una relativa apertura de las normas vitales, la cerrazón de las normas sociales define a la madre como la única responsable del hijo. La madre se constituye como madre por la relación con el hijo, e independientemente de su lazo biológico con el niño. Del lado de las normas sociales, lo maternal continúa siendo femenino, y además constituye la feminidad. El cuidado habría que entenderlo de manera extensa, confrontado a las reticencias masculinas para asumir el cuidado construido socialmente, pues lo maternal somete a las mujeres pero también las construye.

El cuidado comporta una dimensión de apego, pues la privación de apego es patógena en la vida animal, cuya naturaleza es retractable y no garantizada. El cuidado materno es pues necesario para la creatividad vital. Pero ciertos objetos no son suficientes para la vida naciente; es necesario un calor que tranquilice y esta experiencia vivida permite el comienzo de una vida afectiva; los trabajos de Françoise Dolto así lo demuestran. En la naturaleza, el poder de cuidar está disociado del lazo biológico y de la identidad sexual. Un macho puede responsabilizarse de los pequeños de una hembra y un animal de otra especie puede ocuparse de una cría, tal y como señala Lorenz en sus trabajos sobre los pájaros y los patos (1981).

Además, el apego es independiente del cuidado objetivo (nutrición, higiene). Este apego puede tener por objeto un ser no previsto por la naturaleza pero que responde a las exigencias vitales del ser vivo. El instinto abre aquí una brecha sobre lo disímil, lo inesperado, mientras que la socialidad humana se reduce a modelos preestablecidos. Hay una inventiva propia del ser vivo y a su capacidad de autodeterminación.

\section{La vida enferma}

Sin embargo, el humano vivo tiene como específica su relación compleja con la muerte. JeanChristophe Mino se interesa por el fin de vida propio, y observa que nuestra relación con la muerte ha sido modificada por la irrupción de nuevas formas de enfermedad. En este momento, en el que se 
constata una casi desaparición de las enfermedades infecciosas, las enfermedades crónicas letales están en pleno desarrollo a causa del alargamiento de la esperanza de vida. Necesitamos hacernos con esta nueva situación que desconcierta a las prácticas médicas usuales. Ciertamente, los médicos especialistas no cambian de lógica terapéutica globalmente. Tratan a nivel orgánico de la misma manera a una persona de noventa años que a una de cincuenta, con la particularidad de que, bajo la presión creciente de las lógicas económicas, el racionamiento de cuidados corresponde a las personas de edad más avanzada. En la práctica, los discursos y los usos oscilan entre carencia de cuidados y sobre-tratamiento, incluso encarnizamiento. El procedimiento paliativo es todavía difícil de llevar a cabo en este contexto. Pero ¿se debe intervenir más allá hasta hacer invisible el final de la vida? Técnicamente, los médicos recurren a maneras «rutinarias» de hacer que encajan en las prácticas ordinarias. Intervenir sigue siendo un imperativo moral, lo cual se traduce en una respuesta a los problemas clínicos, pues no aplicar un tratamiento es considerado como algo culpable. Sería ir contra una mejora, aunque ésta fuera mínima. La existencia de opciones terapéuticas es una fuerte incitación a continuar tratando, de manera que aunque no haya elección de tratamiento, la evidencia del tratamiento se impone sin embargo como una elección ética por defecto en el desarrollo de las enfermedades crónicas.

Sin duda es urgente un cambio de paradigma en la práctica hospitalaria, desde el punto de vista del final de la vida y del deseo - a veces por el paciente- de cese de cuidados. Actualmente, la extrema especialización de los cuidados no facilita este proceso.

Pero el hombre puede también estar enfermo por atracción de la enfermedad. A partir de una cita de El hombre sin atributos — «El hombre agotado se ve atraído por aquello que le es nocivo»-, Arnaud François se pregunta si habría una «salud innata», del mismo modo que, según la paradoja estoica, habría una manera enferma de estar enfermo.

En primer lugar, se puede proponer un acercamiento psicoanalítico de esa paradoja. En efecto, el organismo trata de suprimir toda tensión, lo que no deja de suscitar preguntas. Freud las aborda en Más allá del principio de placer definiendo esta ausencia de tensión como principio cero o inercia. La segunda tendencia que se puede evocar es el principio de constancia; según la tercera, controlar las tensiones remite al masoquismo primario.

Esos tres niveles son a menudo conjuntos en Freud. Este análisis será recogido por Laplanche en Vida y muerte en psicoanálisis. Pero esta tríada es problemática en la medida en que se puede entender la pulsión de muerte como neutralización de las tensiones o como búsqueda del masoquismo en tanto que desagrado. Freud funda a partir de aquí la diferencia entre satisfacción y goce (masoquista).

Derrida propone otra interpretación, esta vez de orden social, en Voyous. La enfermedad autoinmune es otro elemento del querer morir. Derrida ha interpretado filosóficamente esas enfermedades como «pulsión de muerte» inherente al organismo en la medida en que hay identidad entre lo que destruye y lo que es destruido en circularidad catastrófica que mantiene la lesión inicial. De este modo, la sociedad encontraría en el terrorismo islamista su propio y semejante retoño. La analogía con la 
medicina se impone en torno a la idea según la cual hay toxinas internas y externas. Los anticuerpos pueden pues enfrentarse con el organismo.

Se han propuesto varias interpretaciones de este deseo de muerte. Ese deseo es una lucha por el reconocimiento, asunto del que da testimonio la biografía de Baudelaire escrita por Sartre. Existe una elección de fracaso que tiene por origen la mala fe y la angustia inducida por la libertad. La ideología de la «degeneración» — desde finales del XIX— abre otra pista. Hay una teoría vitalista francesa nacida de la observación de la tuberculosis incurable en el XIX, en el momento en el que se llamaba «degenerativas» a las enfermedades cuyo principio no era conocido (las enfermedades reumáticas, por ejemplo).

Cada persona tendría tendencia a volver a la conformación originaria de su especie. Esa vuelta de péndulo se convierte en imposible en ciertas especies, y de ahí esa inexorable degradación. Así pues, los daños acumulados por un individuo se transmitirían; a pesar de su debilidad teórica, esta doctrina desarrollada en el Traité des dégénérescences inspiró a Zola. La doctrina puede también haber encontrado inspiración en la constatación banal de la ausencia de acuerdo entre lo vivo y aquello de lo cual éste necesita. De ahí el círculo vicioso y las reacciones en cadena de las enfermedades «automantenidas». Se trate del miedo del paciente a perder a su terapeuta o se trate de la constatación de Nietzsche según la cual uno prefiere querer lo negativo a no querer nada, esta negatividad debe poder ser pensada como interna a la vida.

La obra de Patrick Autréaux ( $D u$ dedans des choses, 2012) parece constatar igualmente esa paradoja de un poder de la vida que se expresaría como poder de destrucción de uno mismo del cual da prueba la enfermedad mortal. El autor, que padecía un linfoma, cuenta su cura y la contrariedad que la vuelta a la salud supuso en una obra autobiográfica de título Dans la vallée des larmes.

Claire Marin observa que, oponiéndose al topos de la curación gozosa, el autor señala la fuerza del deseo de vivir en la enfermedad y una renovada atención a lo vivo. La curación es pues una pérdida dolorosa al tiempo que un alivio y la enfermedad aparece como una experiencia de vida intensa. La curación es comparada a un duelo sin difunto en el que el presente entra en calma chicha, el viento cesa de tal manera que la relación del psiquiatra que es el autor con los pacientes (de urgencias psiquiátricas) cambia. Algo se ha desgarrado en su mundo; lo vivo se encuentra entonces confrontado con lo que se podría llamar una riqueza del desastre.

La cuestión de la vulnerabilidad de la vida se halla en el centro de la comunicación de Yvon Inizan, que pone frente a frente la obra de Annie Ernaux Ecrire la vie y la de Ricoeur La Mémoire, l'Histoire, l'Oubli. La obra concebida como epitafio por Ricoeur hace que vida y escritura se cuestionen mutuamente. Hay, además, una dimensión volitiva y no fenomenológica de la percepción (Merleau-Ponty). Esta concepción pone en evidencia el límite de la descripción eidética de Husserl. La descripción empírica atañe a hechos, y lo voluntario e involuntario están referidos a una intencionalidad, asunto del que no se puede prescindir si no es eliminando también lo vivo.

Lo voluntario y lo involuntario presentan la relación con el pensamiento que se descubre como participación en una vida (una voluntariedad que tiene que ver con mi cuerpo) y que es de un orden 
diferente al de la relación con las cosas exteriores objetivas. De esta suerte, la memoria traza otras vías en ese texto de Annie Ernaux y en Les Années, vías que no son el camino de la autobiografía-confesión tradicional. Describir lo que no es objeto de una visión sino de una participación en una historia colectiva que liga a los vivos de una época; no se trata de «acontecimientos» sino de lo que hace que un mundo sea compartido. En este pensamiento de la vida, el hecho de habitar un cuerpo mortal es determinante, pues la incompleción y la herida son lo que nos inicia en lo viviente.

Annie Ernaux rehúsa así pues capturar la vida fuera del punto de vista del ego. Con una especie de suspensión de la autoridad, hace sitio al recuerdo de la época en la que se ha vivido. Nada organiza el texto de manera finalista. La vergüenza (tema recurrente en su obra) es vista como una forma de la herida y organiza un movimiento de la vida activa y pasiva que se experimenta en el tiempo, y en su acabamiento.

\section{Lo vivo sometido a prueba por las artes}

Nathalie Zaccaï-Reyners nos ha llevado a compartir la experiencia singular de un artista fracasado. En On Not Being Able to Paint, Marion Milner evoca su relación con la pintura. Aunque domina perfectamente las técnicas clásicas, sin embargo es incapaz de pintar siguiendo las reglas que le han enseñado; el dibujo académico remite a falsificaciones y no al mundo vivo que tenemos delante. En una serie de cuadernos de notas se aplica a alcanzar la vida de los objetos mediante el relato de una experiencia perceptiva, y al mismo tiempo plantea cuestiones sobre la institución del «uno mismo» en la sociología y la filosofía moral. Además de las disposiciones jurídicas y la educación en benevolencia, queda un sustrato de recurso moral poco organizado; el del sentido común y la imaginación cultural. Al hilo de la lectura de textos, Nathalie Zaccaï-Reyners también se plantea preguntas sobre el papel de la imaginación en la vida moral. A través de Martha Nussbaum, por ejemplo, ¿cómo pensar la disposición hacia la empatía que la habita? La ficción sería fuente de aprendizaje virtuoso pues una imaginación viva lo acoge todo, incluso los monstruos.

Olivier Goulet, bioplástico, presenta a continuación su obra Corps EXT. Se trata de un experimento artístico de lo vivo. El artista está vestido con una capa formada por una serie de moldes de rostros humanos, y lleva un sombrero que imita la piel humana. Su procedimiento, que se puede situar dentro del «bio-arte» -ilustrado entre otros por Eduardo Kac- y que él mismo define como transhumanista, se sustenta en cinco puntos:

- la piel, ilustrada por «skin bags» en los que el cuerpo se presenta de forma desnuda a través de los objetos que evocan la muda: burka de piel o bolsa.

- el esqueleto, producto del hombre biónico con un ojo occipital y una pantalla que supone una visión aumentada al tiempo que la idea de sobrevivirse a uno mismo.

- la transcorporación plantea la pregunta sobre el momento en el que se dejaría de dar a este «ser» el nombre de «humano». Diversos trozos de su cuerpo se 
encuentran dispuestos sobre una estantería. La desaparición del rostro sería sin duda más determinante que la de los órganos vitales. La conciencia implica una renovación celular continua. Si la prolongación o el lazo de unión entre los dos estados fuera el «metacórtex», se trataría entonces de optimizar la coherencia cerebral.

- la «rez» de cerebros (prospección del cuerpo social) presenta cerebros conectados por cables entre ellos, símbolo de lo que a todos nos une. Ese lazo estructura nuestras relaciones sociales y supone un equilibrio entre florecimiento individual y socialidad. Constituye también una alegoría política de un sistema de voto directo «óptimo $\mathrm{O}$ ».

- «Human profil» es alguien que mira y que se proyecta con tamaño real en una imagen. Entonces entran en juego complejas interacciones. La silueta imprecisa puede sugerir que se trata de dios. «Digital» sería un dios perfecto que produce objetos infiltrados en lo cotidiano.

Se trata pues de una experiencia de laboratorio, de un abordaje trans-media, metafórico. Cada dibujo está contado como una aventura de la vida y se acompaña a menudo con un movimiento de danza que le da su particular ritmo.

Pero hablar de un coloquio en Cerisy sin evocar las noches en el desván sería pasar por alto una parte esencial de los momentos de reflexión y encuentro. La proyección del espectáculo de Alain Prochiantz dirigido por J.-F. Peyret Ex vivo / in vitro, presentado en el teatro de la Colina y filmado, abre las veladas con una presentación escénica de los avatares de la procreación artificial y de las reflexiones que suscita en los actores, que improvisan una parte de su texto en función de las preguntas que suscita el tema.

Se presenta a continuación lo vivo visto desde Extremo Oriente mediante una reflexión sobre la pintura china en su relación con la perspectiva, a cargo de Jacques Gies, y a continuación sobre las lecturas de Bergson en Japon (Shin Abiko) y finalmente la presentación por parte de Paul Dumouchel de una criatura artificial, Pao, pequeño robot que imita al ser vivo y crea un fenómeno social en los hospitales donde ha sido experimentado. Algunos jóvenes investigadores han tenido también la posibilidad de presentar su trabajo, con abordajes originales; ecocrítica, relecturas del concepto agambiano de «vida desnuda» o relectura de la obra de Bergson y exégesis de algunos textos de Ruyer o de Simondon.

La presentación a manos de Nathalie Zaccaï-Reyners de la película realizada por su hermano sobre su abuela Mariette aborda con tacto la enfermedad de Alzheimer, las dificultades de encontrar plaza en un centro especializado y el riesgo de maltrato de las personas al final de su vida.

El coloquio se termina gozosamente con una sorprendente representación de d'Emmanuel Lascoux (piano y voz), Samuel Lascoux (violonchelo) y Guillaume Boussard (traducción y voz). El texto De Natura Rerum resuena en latín (esa lengua que dicen «muerta»), en traducción, acompañado 
de un concierto de piano y chelo, percusiones y representación teatral que sugiere (en ocasiones con humor) las transformaciones de la materia y la plasticidad de lo vivo. En resumen, este coloquio sobre lo vivo fue un coloquio... vivo en el mejor sentido del término.

(Traducción de Amelia Gamoneda.)

\section{Bibliografía}

AMEISEN, J.-C. (2002): La sculpture du vivant; le suicide cellulaire ou la mort créatrice. Paris, Seuil. BARBARAS, R. (2011): La vie launaire. Paris, Vrin.

Descola, Ph. (2006): Par delà nature et culture. Paris, Gallimard.

EsPÓSITO, R. (2012): Comunità e biopolitica. Milano, Mimesis.

LATOUR, B. (2000): «Biopouvoir et vie publique», Multitudes, 1, pp. 94-98.

LORENZ, K. (1981): L'homme dans le fleuve du vivant. Paris, Flammarion.

SIMONDON, G. (1995): L'individu et sa genèse physico-biologique. Grenoble, Jerôme Millon. 